from another specimen. In this new photograph the great toe is large and diverges from the other toes as in my Fig. 2 (here printed). But its terminal phalanx is flexed and the foot is so posed that the great digit projects over and in front of the bases of the other digits and is consequently foreshortened in the photograph. The shape of the plantar surface and that of the heel is not that shown in the photograph of Mr. Akeley's cast-but is that already familiar to those who have made a study of the gorilla's foot. It is a happy circumstance that $\mathrm{Mr}$. Akeley presents his readers with conclusive evidence condemning his plaster cast of the gorilla's foot, side by side with the photograph of that misleading production (which faces p. 242). He could not deal more frankly and straightforwardly with the matter than this.

October 5 .

\title{
Determination of the Temperature of the Upper Atmosphere by Meteor Observations.
}

IN a letter published in NATURE for February Io, I923 (p. I87), I referred to the possibility of determining the temperature of the upper atmosphere on any occasions when the disruption of a meteor has been heard and the time interval between sight and sound has been recorded. I have now to report that I have only been able to learn of two instances which have looked favourable, and that neither of them has yielded useful information.

The first case is that of the meteor of December 2I, I876, which is described in the American Journal of Science and Arts, Series III., Vol. I3, p. I66, I877, and in a paper by Prof. C. U. Shepard, on p. 207 of the same volume, as well as in a paper read by Prof. D. Kirkwood before the American Philosophical Society, March I877. The meteor was under observation from Kansas to the shores of Lake Erie.

Over the State of Missouri one or more explosions occurred, and the disintegration continued until there was " a large flock of brilliant balls chasing each other across the sky." In some places " a terrific series of explosions were heard." It is clear that the identification of the source of any particular sound is out of the question. The following tantalising observation quoted by Kirkwood is therefore of no service: " Rev. James Garrison, who resides one mile south of Bloomington, noticed by his clock the time of the meteor's disappearance and also that of the subsequent rumbling sound, together with the violent jarring of his house. The interval was I5 minutes, indicating a distance of I85 miles.' The implication that the speed of sound is a universal constant is to be noted.

The second case is that of the meteor of July 27, I 894, a very detailed account of which is given by Prof. E. S. Holden in "Meteors and Sunsets" (Contributions from the Lick Observatory, No. 5). It is clearly established that the meteor exploded at a height of about 28 miles and near to Merced, California. The determination of the time of passage of the sound to the Lick Observatory appears from the statements of the observers to be precise enough. Five observers who noted the time at which the sound was heard agree within two or three seconds. For the time at which the explosion was seen there is, however, only one observation with any claim to precision.

The time of explosion (A. F. Poole)

The time of hearing the report (five observers) .

Time of passage of sound .

7h. $29 \mathrm{~m} .45 \mathrm{~s} . \pm \mathrm{IOS}$.

7h. $36 \mathrm{~m}$. I $4 \mathrm{~s} . \pm 3 \mathrm{~s}$. 6m. 29s. \pm I 3 s.
The distance from the observatory to the point at which the explosion occurred is estimated by Holden as $59^{\circ} 3$ miles - i.e. $95 \mathrm{~km}$., due allowance being made for the height of the observatory above sea-level.

The data imply that the average speed of the sound was $244 \pm 8$ metres per second, and that the average temperature of the air between 28 miles and I mile above sea-level was $148^{\circ} \pm 9^{\circ} \mathrm{A}$. (about - I93 ${ }^{\circ} \mathrm{F}$.).

In r894 such an estimate was accepted without difficulty. In I923 it looks wrong. The most likely place for a flaw is in Poole's observation. There is no statement as to how it was made: if with an ordinary watch an error of a whole minute is not unlikely. With the appropriate amendment the time of travel of the sound becomes $5 \mathrm{~m}$. 29s., the speed 289 metres per second, and the temperature $207^{\circ} \mathrm{A}$.

Some contirmation is found in the only report received by Prof. Holden in which a single observer states the interval between sight and sound of the explosion. Mr. George Bray saw the whole phenomenon at Santa Clara, and gave the interval as $7 \frac{1}{4}$ minutes. According to Holden's sketch-map, the horizontal distance was 70 miles, the path of the sound was therefore about 75 miles or I2I km., and the speed 278 metres per second. This corresponds with an average temperature $192^{\circ} \mathrm{A}$. and is quite plausible, but with the limitations implied by an estimate of $7 \frac{1}{4}$ minutes, little weight can be attached to the result.

I have trespassed so far on your space because I wish to emphasise the fact that any one who has the good fortune to see a meteoric explosion will be doing good service if he notes the time by his watch (writing it down immediately) and listens for the sound. If he is able to compare his watch with a standard clock, so much the better, but from the present point of view the interval is of greater importance.

In conclusion, I should like to thank Miss Williams, assistant secretary of the Royal Astronomical Society, who devoted much time to looking through the literature of meteors on my behalf.

\section{Addison Road, Bedford Park, W.4, October 25.}

\section{Experiments on Ciona intestinalis.}

IN the issue of NATURE for November 3, p. 653 , there appears a letter from my old friend and former colleague, Mr. H. M. Fox, in which he records an attempt which he made this summer to repeat Dr. Kammerer's experiments on Ciona. These experiments consisted in inducing an abnormal growth of the siphons of Ciona by repeated amputation. $\mathrm{Mr}$. Fox amputated the siphons of Ciona, but the length of the regenerated siphons was normal.

As Dr. Kammerer took a deep interest in the projected repetition of his experiments on Ciona, and wrote to me twice this summer to learn if repetition were being attempted and under what conditions, perhaps you will allow me to make some remarks on Mr. Fox's letter, as Dr. Kammerer is now in America.

Dr Kammerer, whilst in Cambridge, wrote out a full account of the precautions to be observed in making these experiments. At that time he did not know that Mr. Fox was going to take up the work: another Cambridge biologist had undertaken to do so, but this gentleman was prevented by illness from doing the work. To him, however, Dr. Kammerer had transmitted his information. I understandMr. Fox will correct me if I am wrong-that Dr. Kammerer's instructions did not reach Mr. Fux. 